\title{
Waterborne Disease Risk Factors and Intervention Practices: A Review
}

\author{
Winfred Mbinya Manetu*, Amon Mwangi Karanja \\ Department of Geography, Egerton University, Nakuru, Kenya \\ Email: ^bnyaw2015@gmail.com
}

How to cite this paper: Manetu, W.M. and Karanja, A.M. (2021) Waterborne Disease Risk Factors and Intervention Practices: A Review. Open Access Library Journal, 8: e7401.

https://doi.org/10.4236/oalib.1107401

Received: April 9, 2021

Accepted: May 15, 2021

Published: May 18, 2021

Copyright $\odot 2021$ by author(s) and Open Access Library Inc.

This work is licensed under the Creative Commons Attribution International License (CC BY 4.0).

http://creativecommons.org/licenses/by/4.0/ (c) (i) Open Access

\begin{abstract}
Waterborne diseases remain a major global public health issue and a great environmental concern and the outbreak is common in African countries. Illness due to waterborne diseases causes morbidity and mortality in less developed countries among children aged below 5 years. This study was aimed at reviewing literature on past and present studies on waterborne diseases, the risk factors as well as the intervention practices. The unavailability of piped water and dependence of rural dwellers on surface waters which are often contaminated with fecal materials are the major causes of the rising prevalence of waterborne diseases. Poor hygienic practices have also been found to play significant role in the spread of waterborne diseases. Besides, poor environmental practices such as lack of sanitation facilities encourages spread of liquid and solid wastes within residential areas contributing to the increasing waterborne illness. Improvements in drinking water, sanitation facilities and hygiene practices in less developed countries have been suggested by many studies as key interventions to reduce waterborne diseases.
\end{abstract}

\section{Subject Areas}

Environmental Sciences, Public Health

\section{Keywords}

Water, Waterborne Disease, Factors, Interventions and GIS

\section{Introduction}

Water is important to human life and public health. However, much of the world's population lacks access to adequate and safe drinking water. Currently, water scarcity is a global challenge that affects more than $40 \%$ of the total global population [1]. In addition, it is estimated that around 3 billion people will not have 
access to fresh water by 2025 and will be living in a water stressed environment [2]. As a result, water-related diseases and deaths continue to be a global burden in both developed and developing countries. Though most cases are reported in less developed countries, developed countries also experience waterborne diseases outbreaks [3] [4] [5].

Waterborne diseases are caused by drinking water mostly contaminated by human or animal excrement which contain pathogenic micro-organisms. Globally, waterborne diarrhea illness is leading among diseases that cause mortality and morbidity, killing 1.8 million people and causing approximately 4 billion cases of illness annually [6]. Moreover, in less developed countries waterborne diarrhea continues to be a leading cause of death and illness among children with $90 \%$ of diarrhoeal deaths being borne by children under five years [7]. Poor sanitation, inadequate safe drinking water and poor hygiene practices are major attributable factors to waterborne diseases occurrence, [8] [9] [10] [11]. Besides, WHO estimates that, $6.3 \%$ of all deaths are caused by limited access to safe drinking water, improved sanitation facilities and hygiene practices as well as water management that reduce transmission of waterborne illness [12]. According to [7], 780 million of the total global population do not have access to safe water, and an estimated 2.5 billion people in developing world live without access to adequate sanitation. However, supply of clean drinking water is one of the main challenges facing most of the African countries today [13].

In Africa, it is estimated that only $22 \%$ of the population has adequate sanitation facilities [14]. Additionally, $28 \%$ of the population of sub-Saharan Africa defecates in the open and an additional $23 \%$ use "unimproved" sanitation facilities that do not ensure hygienic separation of human excreta from human contact, [15]. Moreover, even where clean water and flush toilets are available in Africa, lack of hygiene awareness continues to result in outbreaks of water related diseases. In the Kenyan context, waterborne diarrhea diseases have been reported to be among the major public health problems. This is mostly associated with poor environmental sanitation, poor hygiene practices as well as poor supply of safe and clean drinking water [16]. Water predicament remains very critical in Kenya and the country has been classified among the water scarce countries in the world with only $647 \mathrm{~m}^{3}$ per capita against $1000 \mathrm{~m}^{3}$ standard global benchmark [17]. Additionally, according to Ministry of water and Irrigation report (2012), 50\% of the Kenya's households did not have access to safe drinking water and the proportion for the poor households was higher, [18]. Most of the Kenyan rural populations obtain their water supplies from unprotected sources, underground water, streams, spring wells, ponds and lakes [19] making them frequently subjected to diarrhea diseases.

Consequently, better understanding of waterborne disease occurrence can perhaps help reduce associated morbidity and mortality rates. As a result, the main aim of this study was to conduct a systematic review on occurrence and burden of waterborne diseases. The broad objective of this study was to review present and past researches on waterborne diseases and most importantly the 
contributing factors for waterborne diseases as well as the intervention practices. Therefore, the present study gives the detailed information on the empirical studies of the past and present waterborne diarrhoeal diseases. The review gives the relevant information to understand the burden of waterborne diseases in both developed and developing countries, waterborne disease contributable risk factors, information on waterborne prevention practices and finally identifying potential gaps in studies on waterborne diseases.

\section{Methodology}

Relevant articles and reports were identified by using international databases including Google scholar, PubMed, Web of Science, China National Knowledge Infrastructure and Science Direct. Search key terms included: Water borne diseases, risk factors and intervention practices. Journal articles and reports were limited from 2005 to 2020. Sixty-one reports and journal articles reporting the water borne diseases, associated contributing factors and intervention practices and that met inclusion criteria were included in this review.

\section{Research Findings}

\subsection{Classification of Water Related Diseases}

Water related diseases are due to water associated pathogens. They are also illness related to water shortage or water contamination during adverse climate events, such as floods and droughts, and diseases related to vectors with part of their life cycle in water habitats, [20]. Water diseases are illnesses resulting from direct drinking water indirect exposure of the skin to contaminated water. Fundamentally, water related diseases are classified into four main classes: Waterborne diseases, Water-washed diseases, Water-based diseases and Insect vector diseases.

\subsubsection{Water-Borne Diseases}

Waterborne diseases are those diseases that are transmitted through the direct drinking of contaminated water with human or animal excreta [21]. Contaminated drinking water when used in the preparation of food can be the source of food borne disease through consumption of the same microorganisms. Most waterborne diseases are characterized by diarrhoea, which involves excessive stooling, often resulting to dehydration and possibly death. According to [21] approximately 4 billion cases of diarrhoea reported each year cause at least 1.8 million deaths with $90 \%$ of the cases being children under the age of five years. These deaths represent approximately $4 \%$ of all deaths, and $18 \%$ of children under-five years' deaths in developing countries, diarrheal disease accounts for an estimated $4.1 \%$ of the total daily global burden of disease and is responsible for the deaths of 1.8 million people every year and mostly concentrated on children below 5 years in developing countries.

Most waterborne diseases are often transmitted via the fecal-oral route, and 
this occurs when human fecal material is ingested through drinking contaminated water or eating contaminated food which mainly arises from poor sewage management and improper sanitation. In rural African regions, fecal contamination of water arises from runoffs from nearby bushes and forest which serve as defecation sites for rural dwellers. Waterborne disease can be caused by protozoa, viruses, bacteria, and intestinal parasites [21]. Some of the organisms remarkable for their role in the outbreak of waterborne disease as shown in Table 1 below include Cholera, Amoebic dysentery, Bacillary dysentery, Cryptosporidiosis, Typhoid, Giardiasis, Paratyphoid, Balantidiasis, Salmonellosis, Campylobacter enteritis, Rotavirus diarrhea, E. coli diarrhea, Hepatitis A, Leptospirosis and Poliomyelitis, [22].

\subsubsection{Water-Washed Diseases}

Water washed diseases are those diseases which thrive in conditions with freshwater scarcity and poor sanitation. Control of water-washed diseases depends more on the quantity of water rather than the quality [21]. Some of the examples of water washed diseases as in Table 1 are; Scabies, Typhus, Yaws, Relapsing fever, Impetigo, Trachoma, and Skin ulcers. Washing and improved personal hygiene play an important role in preventing water-washed disease transmission [21].

\subsubsection{Water-Based Diseases}

Water-based diseases are infections caused by spread of organisms that develop in water and become human parasites. Water-based disease are also infections

Table 1. Classification of water related diseases.

\begin{tabular}{|c|c|c|}
\hline Class & Route Cause & Disease \\
\hline Water-borne & $\begin{array}{l}\text { Drinking contaminated } \\
\text { water }\end{array}$ & $\begin{array}{l}\text { Cholera, Amoebic dysentery, Bacillary } \\
\text { dysentery (shigellosis), } \\
\text { Cryptosporidiosis, Typhoid, } \\
\text { Giardiasis, Paratyphoid, Balantidiasis, } \\
\text { Salmonellosis, Campylobacter enteritis, } \\
\text { Rotavirus diarrhoea, E. coli diarrhoea, } \\
\text { Hepatitis A, Leptospirosis and } \\
\text { Poliomyelitis [21] [22] [24]. }\end{array}$ \\
\hline Water-Washed & $\begin{array}{l}\text { Lack of clean water for } \\
\text { washing. }\end{array}$ & $\begin{array}{l}\text { Scabies, Typhus, Yaws, Relapsing } \\
\text { fever, Impetigo, Trachoma, } \\
\text { Conjunctivitis and Skin ulcers. }\end{array}$ \\
\hline Water-Based & $\begin{array}{l}\text { Host organisms that } \\
\text { develop to human } \\
\text { parasites. }\end{array}$ & $\begin{array}{l}\text { Schistosomiasis, Dracunculiasis, } \\
\text { Paragonimiasis and Clonorchiasis. }\end{array}$ \\
\hline Insect-Vector & $\begin{array}{l}\text { Organisms that need } \\
\text { water to breed. }\end{array}$ & $\begin{array}{l}\text { Mosquito-borne diseases; Malaria, } \\
\text { Yellow fever, Dengue fever, Filariasis and } \\
\text { Fly-borne diseases; Onchocerciasis } \\
\text { (river-blindness), Trypanosomiasis } \\
\text { (West African sleeping sickness), } \\
\text { Leishmaniosis (Kala-azar), Loiasis, [21] }\end{array}$ \\
\hline
\end{tabular}


caused by parasitic pathogens found in aquatic host organisms [21]. These host organisms mostly include; snail, fish, or other aquatic animal. Humans usually become infected by ingesting the infective forms or through skin penetration. Examples of water based diseases include Schistosomiasis, Dracunculiasis, Paragonimiasis and Clonorchiasis, (Table 1). These diseases can be prevented through avoiding contact with contaminated water or use of protective clothing or barrier creams.

\subsubsection{Insect-Vector Diseases}

These are diseases which are not directly related to drinking water. They are those diseases that are caused by insect vectors such as mosquitoes and flies which needs water to breed [21]. Humans beings become infected by being bitten by these insect vectors. However, consideration of vector control during the design, construction and operation of surface water reservoirs and canals can reduce the potential for water related disease transmission. Prevalence of water related diseases are high in tropical Africa as a result of poor environmental management and sanitation. Drainages are often waterlogged, hence constituting breeding sites for these insect vectors. Malaria is one of the water related diseases endemic with an estimated 212 million cases of malaria reported globally. Most of the cases reported in 2015 were in African Region (90\%), followed by South-East Asia Region (7\%) and Eastern Mediterranean Region (2\%) [23].

\subsection{Waterborne Disease Contributing Factors}

Waterborne diseases outbreaks increase where standards of water, sanitation and personal hygiene are low [25]. According to [26], waterborne diseases are highly attributable to lack of clean and safe drinking water, poor sanitation and hygiene practices. Additionally, research indicates that more than half of acute illnesses are attributable to water, sanitation and hygiene-related across all age groups. Water related diseases are commonly reported in low-income countries as provision of safe water, sanitation and hygiene is sub-optimal as compared to developed countries which has more water resources. As well, even with more resources in developed countries, pumps, pipes and purification facilities could fail leaving people susceptible to waterborne diseases.

Several studies have revealed the significance of water quality, sanitation and hygiene in explaining the occurrence of waterborne diseases. For instance, in a study that was done in Ile-Ife, Nigeria in an attempt to assess and map the incidence factors responsible for the spread of water borne diseases [27] found that, most of the reported cases of water borne diseases were due to environmental factors such as poor environmental sanitation, indiscriminate waste disposal, effect of age-long communal crisis, low topography and swamps that led to high microbial growth, water hardness and high $\mathrm{pH}$ of the wells and borehole water in the area. According to [11], endemic pattern of diarrhea in Mexico City reflected mostly inadequate housing, sanitation, and water-related practices.

Similar findings on poor hygiene practices have been reported in Mbeere 
County, Kenya [9] where waterborne diseases infections and those who washed vegetables and fruits before cooking were strongly correlated. According to [10] there was a high prevalence of waterborne diseases in Nakaloke sub-County, Uganda there was association between poor sanitation and hygienic conditions that included poor siting of sanitary facilities and closeness of pit latrines near water sources. Eating food out after school hours is another poor hygiene practice which was found to cause waterborne diseases in a study conducted among male schoolchildren in Jedida city in Saudi Arabia [28]. The explanation if this being that they consumed food from outside kiosks which was probably cooked by contaminated water. The same study also points out the effects of sanitation as a key factor to waterborne diseases. Sewage spillage were found to highly susceptible to waterborne diseases due to contamination of their available water resources.

\subsection{Waterborne Disease Prevention Practices}

World Health Organization (2007) estimates that $94 \%$ of waterborne diarrhoeal cases are preventable through changes to the environment which includes interventions to increase the availability of clean water for drinking and to improve sanitation and hygiene practices. In addition, a 2005 systematic review concluded that diarrhoeal episodes are reduced by $25 \%$ through improving water supply, $32 \%$ by improving sanitation, $45 \%$ through hand washing, and by $39 \%$ via household water treatment and safe storage [29]. Other interventions to reduce waterborne diseases are improvements in drinking water, hygiene practices and sanitation facilities and in less developed countries.

For instance; A study that was conducted on preventing diarrhoeal occurrence in a high-risk rural Kenyan population through point-of-use chlorination, safe water storage and rainwater harvesting found that chlorinating stored water used for drinking to improve its quality and use of narrow mouthed and covered containers to prevent stored water from contamination all decreased diarrhoeal risk to the population and encouraged good health, [30]. Similar findings in Bolivia and Bangladesh [31] [32] [33] found that improving water quality through chlorine disinfection and storage in an appropriate container significantly improved the microbiological quality of non-piped household drinking water and reduced the risk of waterborne diarrhoeal diseases.

Poor hygiene practices can encourage waterborne illnesses. According to Al-Ghamdi et al. (2009) children who washed and never dried up their hand or used reusable cloths or sponges to dry dishes before eating had high risks to diarrhea diseases in Jeddah City, Saudi Arabia [28]. Consequently, improving on hygiene behavior can reduce the chances of conducting illness. Benefits of hygiene improvement on reduction of waterborne diseases is reported in a study which was done in Bamendankwe Municipality-North West Cameroon found that majority of people affected by water borne disease were those who didn't not practice regular hand washing before eating food [34]. According to Brooks 
et al., (2003), promoting handwashing after defecation was protective and reduced the burden of illness from bloody diarrhea while limiting injudicious antimicrobial use in Kenya, [35].

Sanitation interventions have been found necessary in preventing waterborne diseases occurrence. Sanitation facilities such as latrines, toilets effective drainage are crucial in separation of human fecal or other wastes which can contaminate water used by humans for drinking if not well managed. A study on spatial analysis of factors Responsible for Incidence of Water Borne Diseases in Ile-Ife, Nigeria found that most cases that were reported from water borne diseases were due to factors like poor sanitation; where majority of the residents with illness were using open-pit toilets and were living near market center where large wastes were generated and improperly disposed in the nearby stream, [27]. According to Brooks et al. (2003) and Garrett et al., (2008) presence of latrines in a household was found to decrease diarrhea risk in Kenya. This is because the presence of a latrine ensures no open defecation which can contaminate water from open sources like river during run off hence reducing waterborne diseases infection.

\section{Conclusions}

The importance of water to man cannot be over emphasized, however its role as vehicle in the transmission of pathogenic organisms has become a source of concern and fear as he cautiously scrutinizes every drop of water before consumption. Unfortunately, the cost of safe drinking is high and only few people can afford while majority rely on the available water sources irrespective of their physical, chemical and biological state. As a result, water related diseases have taken over other diseases and have been one of the leading causes of death and illness globally. The diseases have been reported to affect children under 5 years. However, the analysis of water borne diseases and their risk factors has become an evolving art which requires some sought of professionalism. Most of the studies on waterborne diseases in developing countries [9] [10] [36] [37] have been carried out and most of them so far have focused solely on the risk factors that cause the diseases and characteristics of the individuals affected. Although such studies are very crucial in understanding the effects of water borne diseases, they omit the spatial-temporal variations and regional considerations of the critical risk factors. Additionally, such studies also fail to delineate territories at high and low risk of the disease which is usually very useful to health officials. Health levels vary substantially from one region to another and it is therefore necessary to characterize these regional variations and identify areas with an accumulation of health problems for epidemiological research, and to allow appropriate public health policy decisions [38].

Advances in Geographical Information Systems (GIS) technology provide new opportunities for environmental epidemiologist to study and understand the relationships between environmental and socio-economic factors and the spatial 
distribution of diseases [39] [40]. For instance, GIS techniques have been employed in the investigation and monitoring of waterborne diseases [41] [42], vector-borne diseases [43] [44] and in environmental health [45] [46]. According to ESRI (2012), GIS modelling techniques provide, efficient, fast and easier to use functions which enable integration of various data sources, their harmonization and combined analysis towards achieving a particular objective, [47]. The benefit of using GIS for analysis of waterborne disease occurrence is that it helps in the initial identification of the main cause, visualization and analyzes the spatial relationship between various factors explaining a certain dependent phenomenon. Validating it with actual statistical data gives confidence in its application as well as a platform for presenting the results from geographical data analysis.

\section{Acknowledgements}

Assistance offered by my lecturer Dr. Amon Mwangi Karanja is highly appreciated. My utmost gratitude for his advice, useful comments and improvements he made on this paper is invaluable.

\section{Conflicts of Interest}

Authors have declared that no competing interests exist.

\section{References}

[1] Guppy, L. and Anderson, K. (2017) Global Water Crisis: The Facts.

[2] Tran, M., Koncagul, E. and Connor, R. (2016) Water and Jobs: Facts and Figures. United Nations World Water Development Report, United Nations, New York, 1 12.

[3] Beaudeau, P., de Valk, H., Vaillant, V., Mannschott, C., Tillier, C., Mouly, D., et al. (2008) Lessons Learned from Ten Investigations of Waterborne Gastroenteritis Outbreaks, France, 1998-2006. Journal of Water and Health, 6, 491-503. https://doi.org/10.2166/wh.2008.051

[4] Blasi, M.F., Carere, M., Pompa, M.G., Rizzuto, E. and Funari, E. (2008) Water-Related Diseases Outbreaks Reported in Italy. Journal of Water and Health, 6, 423 432. https://doi.org/10.2166/wh.2008.063

[5] Craun, M.F., Craun, G.F., Calderon, R.L. and Beach, M.J. (2006) Waterborne Outbreaks Reported in the United States. Journal of Water and Health, 4, 19-30. https://doi.org/10.2166/wh.2006.016

[6] United Nations (2014) Water and Health How Does Safe Water Contribute to Global Health? United Nations, New York, 1-6.

[7] United Nations Children's Fund/World Health Organization (2012) Drinking Water. United Nations Children's Fund/World Health Organization, New York.

[8] Nyagwencha, J.M., Kaluli, J.W., Home, P.G, and Murage, H. (2017) Access to Safe Drinking Water and Water-Borne Diseases in Masaba North District, Kenya. JKUAT Annual Scientific Conference, 688-694.

[9] Njiru, P.K., Stanley, O. and Baraza, L.D. (2016) Sanitation in Relation to Prevalence of Waterborne Diseases in Mbeere, Embu County, Kenya. IOSR Journal of Envi- 
ronmental Science, Toxicology and Food Technology, 10, 59-65.

[10] Abdulkadir, N. and Anandapandian, K.T.K. (2013) The Occurrence of Waterborne Diseases in Drinking Water in Nakaloke Sub-County, Mbale District, Uganda. International Journal of Science and Research, 5, 1416-1421.

[11] Cifuentes, E., Suárez, L., Solano, M. and Santos, R. (2002) Diarrheal Diseases in Children from a Water Reclamation Site in Mexico City. Environmental Health Perspectives, 110, 619-624. https://doi.org/10.1289/ehp.021100619

[12] Prüss-Üstün, A., Bos, R., Gore, F. and Bartram, J. (2008) Safer Water, Better Health. World Health Organization, Geneva, 53.

[13] Naik, P.K. (2017) Water Crisis in Africa.

[14] Batterman, S., Eisenberg, J., Hardin, R., Kruk, M.E., Lemos, M.C., Michalak, A.M., et al. (2009) Sustainable Control of Water-Related Infectious Diseases: A Review and Proposal for Interdisciplinary Health-Based Systems Research. Environmental Health Perspectives, 117, 1023-1032. https://doi.org/10.1289/ehp.0800423

[15] Institute of Medicine (US) Forum on Microbial Threats (2009) Global Issues in Water, Sanitation, and Health: Workshop Summary. National Academies Press, Washington DC. https://doi.org/10.17226/12658

[16] World Health Organization (2008) Communicable Disease Risk Assessment and Interventions: Post-Election Emergency: Kenya February 2008. World Health Organization, Geneva, $22 \mathrm{p}$.

[17] UN (2006) Kenya National Water Development Report: A WWAP Case Study Prepared for the 2nd UN World Water Development Report: Water, a Shared Responsibility (2006). UN-Water/WWAP/2006/12, United Nations, New York, 244.

[18] Ministry of Water and Irrigation (2012) The National Water Services Strategy. Ministry of Water and Irrigation, Dodoma.

[19] AMCOW (African Ministers' Council on Water) (2011) Country Status Overview: Water Supply and Sanitation in Kenya: Turning Finance into Services for 2015 and Beyond. An African Minister's Council on Water Country Status Overview, Nairobi, 1-15.

[20] Stanwell-Smith, R. (2010) Classification of Water-Related Disease. Water and Health, Vol. 1, England.

[21] United Nations Children's Fund (2008) UNICEF Handbook on Water Quality. Waterlines, 13, 8-10.

[22] Cheesbrough, M. (2006) District Laboratory Practice in Tropical Countries Part 2. Cambridge University Press, Cambridge. https://doi.org/10.1017/CBO9780511543470

[23] Centers for Disease Control and Prevention (2016) Centers for Disease Control and Prevention Kenya Annual Report 2016. CDC Kenya, Nairobi, 31.

[24] World Health Organization (2016) Prevention \& Control of Water Borne Diseases. World Health Organization, Geneva.

[25] Europe, W. (2009) Outbreaks of Waterborne Diseases. Assessment, No. December, 1-6.

[26] World Health Organization (2007) The International Network to Promote Household Water Treatment and Safe Storage. World Health Organization, Geneva.

[27] Emmanuel, O.A., Prossy, A., Abdul-Azeez, A.S. and Eunice, S. (2012) Spatial Analysis of Factors Responsible for Incidence of Water Borne Diseases in Ile-Ife, Nigeria. Journal of Sustainable Society, 1, 96-113. 
[28] Al-Ghamdi, M.A., Bentham, G. and Hunter, P.R. (2009) Environmental Risk Factors for Diarrhoea among Male Schoolchildren in Jeddah City, Saudi Arabia. Journal of Water and Health, 7, 380-391. https://doi.org/10.2166/wh.2009.058

[29] Fewtrell, L., Kaufmann, R.B., Kay, D., Enanoria, W., Haller, L. and Colford Jr., J.M. (2005) Water, Sanitation, and Hygiene Interventions to Reduce Diarrhoea in Less Developed Countries: A Systematic Review and Meta-Analysis. Lancet Infectious Diseases, 5, 42-52. https://doi.org/10.1016/S1473-3099(04)01253-8

[30] Garrett, V., Ogutu, P., Mabonga, P., Ombeki, S., Mwaki, A., Aluoch, G., et al. (2008) Diarrhoea Prevention in a High-Risk Rural Kenyan Population through Point-ofUse Chlorination, Safe Water Storage, Sanitation, and Rainwater Harvesting. Epidemiology \& Infection, 136, 1463-1471. https://doi.org/10.1017/S095026880700026X

[31] Sobsey, M.D., Handzel, T. and Venczel, L. (2003) Chlorination and Safe Storage of Household Drinking Water in Developing Countries to Reduce Waterborne Disease. Water Science \& Technology, 47, 221-228. https://doi.org/10.2166/wst.2003.0199

[32] Arnold, B.F. and Colford, J.M. (2007) Treating Water with Chlorine at Point-of-Use to Improve Water Quality and Reduce Child Diarrhea in Developing Countries: A Systematic Review and Meta-Analysis. The American Journal of Tropical Medicine and Hygiene, 76, 354-364. https://doi.org/10.4269/ajtmh.2007.76.354

[33] Fonyuy, B.E. (2014) Prevalence of Water Borne Diseases within Households in the Bamendankwe Municipality-North West Cameroon. Journal of Biosafety and Health Education, 2, Article No. 122. https://doi.org/10.4172/2332-0893.1000122

[34] Fonyuy, B.E. and Innocent, L. (2014) Prevention Practices from Water Borne Diseases within Households Prevention Practices from Water Borne Diseases within Households in the Bamendankwe Municipality-North West Cameroon. Global Journal of Medical Research, 14, 25-35.

[35] Brooks, J.T., Shapiro, R.L., Kumar, L., Wells, J.G., Phillips-Howard, P.A., Shi, Y.-P., et al. (2003) Epidemiology of Sporadic Bloody Diarrhea in Rural Western Kenya. The American Journal of Tropical Medicine and Hygiene, 68, 671-677. https://doi.org/10.4269/ajtmh.2003.68.671

[36] Golicha, Q., Shetty, S., Nasiblov, O., Hussein, A., Wainaina, E., Obonyo, M., et al. (2018) Cholera Outbreak in Dadaab Refugee Camp, Kenya-November 2015-June 2016. Morbidity and Mortality Weekly Report, 67, 958-961. https://doi.org/10.15585/mmwr.mm6734a4

[37] Outwater, A., Pamba, S. and Outwater, A. (2013) Water-Related Diseases of People Using Municipal Wastewater: Risks, Exposure, Effects on Health and Control Approaches in Tanzania. VLIR-UOS, Da res Salaam, 132.

[38] Musa, G.J., Chiang, P.-H., Sylk, T., Bavley, R., Keating, W., Lakew, B., et al. (2013) Use of GIS Mapping as a Public Health Tool-From Cholera to Cancer. Health Services Insights, 6, HSI.S10471. https://doi.org/10.4137/HSI.S10471

[39] Croner, C.M. (2003) Public Health, GIS, and the Internet. Annual Review of Public Health, 24, 57-82. https://doi.org/10.1146/annurev.publhealth.24.012902.140835

[40] Esri (2005) Approaches to GIS Programs in Health Education. Esri, Redlands.

[41] Osei, F.B. and Duker, A.A. (2008) Spatial Dependency of V. Cholera Prevalence on Open Space Refuse Dumps in Kumasi, Ghana: A Spatial Statistical Modeling. International Journal of Health Geographics, 7, Article No. 62. https://doi.org/10.1186/1476-072X-7-62

[42] Nkeki, F.N. and Osirike, A.B. (2013) GIS-Based Local Spatial Statistical Model of 
Cholera Occurrence: Using Geographically Weighted Regression. Journal of Geographic Information System, 5, 531-542. https://doi.org/10.4236/jgis.2013.56050

[43] Pathirana, S., Kawabata, M. and Goonatilake, R. (2009) Study of Potential Risk of Dengue Disease Outbreak in Sri Lanka Using GIS and Statistical Modeling. Journal of Rural and Tropical Public Health, 8, 8-17.

[44] Kala, A.K., Tiwari, C., Mikler, A.R. and Atkinson, S.F. (2017) A Comparison of Least Squares Regression and Geographically Weighted Regression Modeling of West Nile Virus Risk Based on Environmental Parameters. Peer), 5, 1-18.

https://doi.org/10.7717/peerj.3070

[45] Maantay, J. (2002) Mapping Environmental Injustices: Pitfalls and Potential of Geographic Information Systems in Assessing Environmental Health and Equity. Environmental Health Perspectives, 110, 161-171.

https://doi.org/10.1289/ehp.02110s2161

[46] Chakraborty, J., Maantay, J.A. and Brender, J.D. (2011) Disproportionate Proximity to Environmental Health Hazards: Methods, Models, and Measurement. American Journal of Public Health, 101, S27-S36. https://doi.org/10.2105/AJPH.2010.300109

[47] Esri (2012) What Is GIS? 